\title{
Avaliação do comportamento de mistura de argamassas através de reometria rotacional
}

\author{
Mixing behavior of mortars evaluated by rotational \\ rheometry
}

\section{Marylinda Santos de França \\ Fábio Alonso Cardoso \\ Rafael Giuliano Pileggi}

Marylinda Santos de França

Departamento de Engenharia de Construção Civil, Escola Politécnica Universidade de São Paulo Cidade Universitária, Butantã Av. Prof. Almeida Prado, 83, Travessa

São Paulo - SP - Brasil CEP 05508-010 Tel.: (11) 3091-5382 E-mail: marylinda@usp.br

Fábio Alonso Cardoso Departamento de Engenharia de Construção Civil, Escola Politécnica

Universidade de São Paulo

Tel.: (11) 3091-5248 Ramal 5248 E-mail: fabio.cardoso@lme. pcc.usp.br

Rafael Giuliano Pileggi Departamento de Engenharia de Construção Civil, Escola Politécnica Universidade de São Paulo Tel.: (11) 3091-5248 E-mail: rafael.pileggi@poli.usp.br

Recebido em 03/08/11

Aceito em 03/02/12

\section{Resumo}

A

principal etapa de preparação das argamassas consiste na mistura dos materiais sólidos com água. A introdução do líquido conduz a uma série de eventos de aglomeração e desaglomeração no sistema, que, por sua vez, irão resultar em esforços durante essa etapa. Estudos previamente realizados demonstraram a capacidade de mensuração desses esforços através de curvas que relacionam o torque com o tempo em equipamentos como os reômetros. Nessa perspectiva, o objetivo deste trabalho é avaliar como o tempo influencia a energia de mistura e as propriedades reológicas de argamassas de revestimento com e sem a utilização de aditivo dispersante. O material foi misturado no reômetro rotacional do tipo planetário por tempos distintos $(17,47$, 87 e 297 s) e em seguida foi submetido a três ciclos de cisalhamento consecutivos. Em tempos curtos verificou-se que a energia de mistura é baixa, não sendo capaz de romper os aglomerados e homogeneizar o sistema, resultando em materiais reologicamente instáveis e menos fluidos. Por sua vez, a mistura de 297 s demonstrou ser mais eficiente, produzindo uma argamassa estável e fluida. Nas argamassas com o dispersante, os níveis de energia de mistura envolvidos foram mais baixos, e o sistema tendeu a homogeneizar-se mais rapidamente, além de ter resultado em argamassas mais fluidas.

Palavras-chave: Mistura. Argamassa. Reologia.

\section{Abstract}

The main step of mortar processing consists in mixing the powder materials with water. The addition of the liquid into the granular system promotes a set of agglomeration and dispersion phenomena, which result in variations of the forces required to shear the mortar during mixing. Previous studies demonstrated that is possible to measure the mixing energy through torque vs. time curves. The aim of this work is to evaluate the influence of mixing time on mixing and rheological behaviors of a rendering mortar. The material was mixed for different times on a rotational rheometer (17, 47, 87 and 297 s) and then submitted to 3 consecutive shear cycles. At short times, the resulting mixing energy was low and unable to break the agglomerates and to homogenize the system; hence the mortar was rheologically unstable and less fluid. On the other hand, the 297-second mixing was efficient, producing a fluid and stable mortar.

Keywords: Mixing. Mortar. Rheology. 


\section{Introdução}

A mistura de materiais sólidos com líquido é uma importante etapa de preparação das argamassas e pode influenciar tanto no comportamento reológico quanto no desenvolvimento da microestrutura do material, comprometendo seu desempenho final. Uma vez que os aglomerados não são rompidos durante a mistura, podem permanecer não hidratados por longo tempo, transformando-se em fonte potencial de defeitos microestruturais, por não estarem cobertos por produtos de hidratação (YANG; JENNINGS, 1995).

Uma maneira de avaliar o quanto a mistura é eficiente no processo de quebra dos aglomerados é por meio de reometria rotacional, utilizando-se equipamentos como reômetros do tipo planetário, que são capazes de quantificar os esforços produzidos em cada processo de mistura, desde o momento em que o líquido é introduzido no sistema. Esses equipamentos permitem a obtenção de curvas de mistura (torque vs. tempo) e, por conseguinte, a análise do perfil reológico por meio de ciclos de cisalhamento impostos ao mesmo material em análise (PILEGGI; STUDART; PANDOLFELLI, 2001).

No momento em que o líquido é adicionado no sistema, induz à formação de aglomerados, uma vez que ele é responsável pela união de várias partículas finas por forças de adesão, aumentando o esforço para a mistura, e depois pelo surgimento de forças capilares (Figura 1). Os aglomerados consistem de partículas pequenas fortemente ligadas devido ao aumento das forças de Van der
Waals, as quais são superficiais atrativas e de curta distância, e exercem grande influência nas partículas pequenas, que têm elevada área superficial. A presença desses aglomerados conduz à heterogeneidades, sendo o cisalhamento imposto pela mistura o responsável pela quebra desses aglomerados, individualizando as partículas, afastando-as e, assim, facilitando a homogeneização do sistema (VAN DEN DRIES, 2004; PILEGGI, 2001). No sistema proposto, argamassa (agregado miúdo + finos), a presença dos agregados promove também a quebra dos aglomerados; é o chamado efeito do moinho de bolas proposto por Williams, Saak e Jennings (1999), que está relacionado com as interações friccionais entre os agregados avaliados no trabalho de Yammine et al. (2008).

$\mathrm{Na}$ presença de aditivos dispersantes, a quebra desses aglomerados será mais eficiente devido às forças de repulsão que estes promovem, reduzindo, assim, os esforços produzidos durante a mistura. As forças de repulsão podem originar-se a partir de três mecanismos básicos:

(a) desenvolvimento de cargas elétricas na superfície das partículas;

(b) adsorção superficial de polímeros de cadeias longas, que impedem a aproximação das partículas por impedimento mecânico (estérico); e

(c) adsorção de polieletrólitos na superfície das partículas (eletroestérico) (OLIVEIRA et al., 2000).

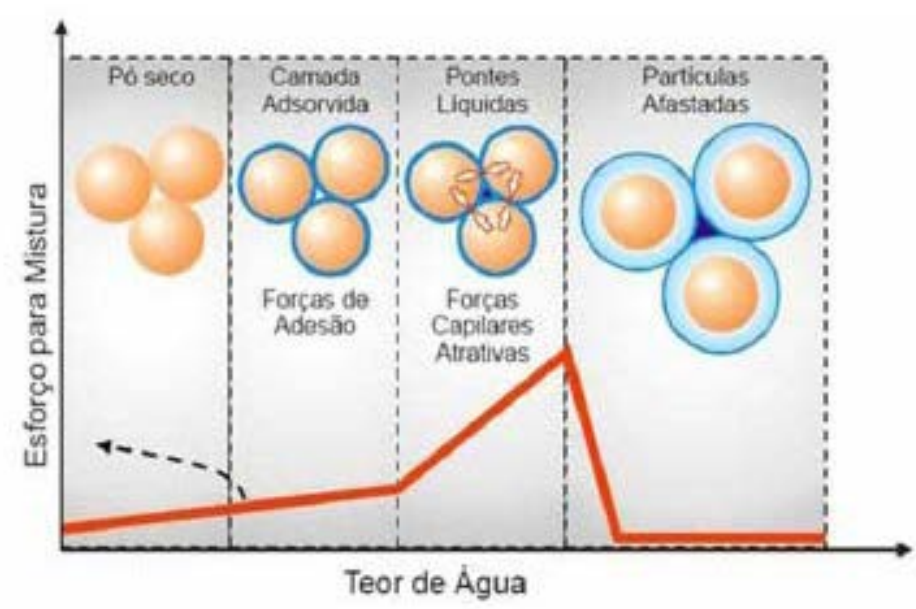

Figura 1 - Representação esquemática das camadas adsorvidas de ligação e das pontes líquidas de ligação entre duas partículas (laranja) imersas num meio líquido (azul)

Nota: Legenda:

Azul claro: líquido de recobrimento da superfície e afastamento das partículas (PILEGGI, 2001); e

Azul escuro: líquido de preenchimento entre os vazios das partículas (PILEGGI, 2001). 
Diferentes condições de mistura implicam distintos perfis de curvas reométricas e, consequentemente, alteram o esforço solicitado, bem como o nível de torque máximo (PILEGGI, 2001; CAZACLIU; LEGRAND, 2008; CAZACLIU; ROQUET, 2009). Os fatores que influenciam no perfil das curvas de mistura podem tanto ser de natureza intrínseca do material, como a distribuição granulométrica do sistema, a área superficial das partículas, a presença de aditivos, entre outros, quanto de natureza extrínseca, que envolve fatores do processo, como, por exemplo, tempo de mistura, forma de adição da água, tipo de misturador, geometria de mistura, velocidade de rotação do equipamento, etc.

Este trabalho, por sua vez, faz uso da técnica de reometria rotacional com o objetivo de avaliar o comportamento de mistura de argamassas de revestimento com e sem a presença de agentes dispersantes submetidas a diferentes tempos de mistura. Contribui, dessa maneira, para um melhor entendimento da eficiência da mistura de argamassas.

\section{Programa experimental}

\section{Materiais}

Uma argamassa de revestimento, DIS, com aditivo dispersante (policarboxilato de sódio) na proporção de 0,0125\% em relação à massa total de sólidos e outra sem a inclusão do dispersante, $\mathrm{REF}$, foram dosadas em laboratório utilizando as seguintes matérias-primas:
(a) cimento CP II F-32;
(b) cal hidratada CH-III;
(c) filer calcário; e
(d) agregado miúdo de areia britada.

A distribuição granulométrica acumulada da argamassa pode ser visualizada na Figura 2, e a distribuição média das fases das argamassas (REF e DIS) no estado fresco está representada na Figura 3. A relação entre água (deionizada) e materiais sólidos utilizada foi igual a 0,16.

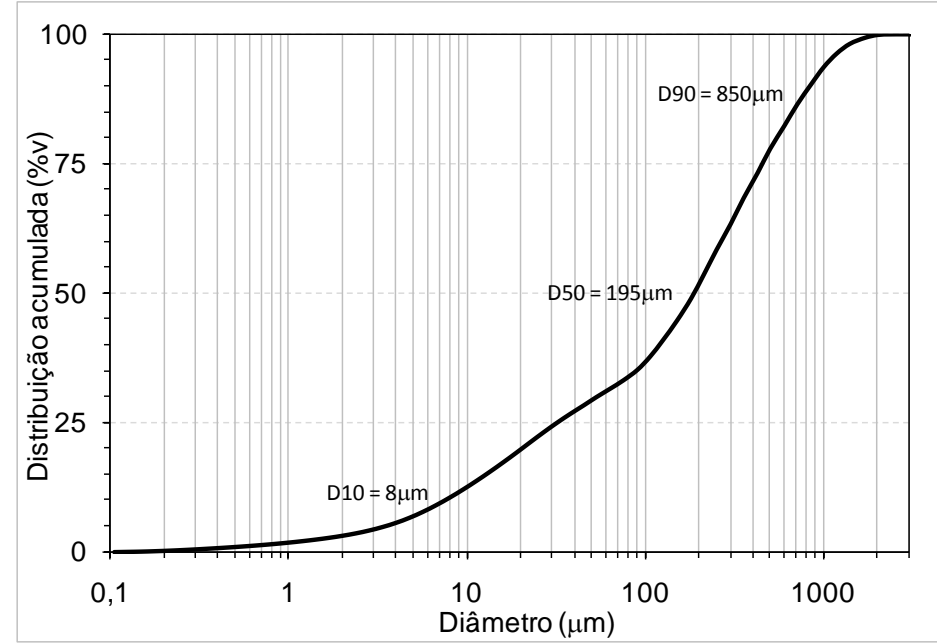

Figura 2 - Distribuição granulométrica acumulada da argamassa

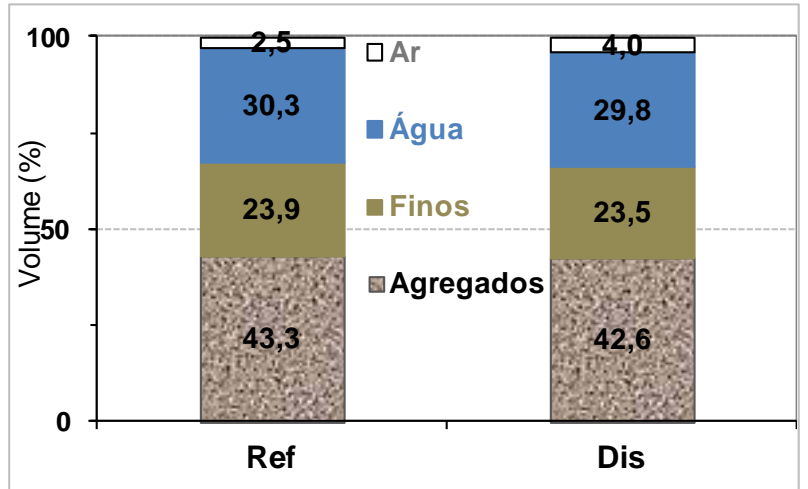

Figura 3 - Distribuição média de fases das argamassas (REF e DIS) no estado fresco - agregados e pasta (finos água e ar) 


\section{Equipamento}

Para avaliar o comportamento de mistura das argamassas quando submetidas aos diferentes tempos, elas foram ensaiadas no reômetro rotacional planetário (Figura 4), desenvolvido na (Poli-USP). Os ensaios são realizados com a geometria de ensaio [6] acoplada no dispositivo rotacional [1], e são medidos os valores de torque necessários para girar a geometria de ensaio com aletas [6] em função da rotação empregada. Todas as operações de controle operacional, coleta e armazenamento de dados são feitas através de software de controle [3] (CARDOSO, 2009).

\section{Procedimento}

Amostras de $4 \mathrm{~kg}$ das argamassas estudadas foram vertidas no recipiente de mistura.
Com o equipamento em rotação constante de 126,5 rpm, a água (640 g) foi adicionada ao material seco de forma direta, com vazão média em torno de 128 g/s. Foram avaliados quatro diferentes tempos de mistura (17, 47, 87 e 297 s), e para cada tempo o material foi submetido a três ciclos de cisalhamento consecutivos, a fim de caracterizá-lo reologicamente. Os ciclos de cisalhamento foram obtidos imediatamente após a mistura, realizados no mesmo equipamento.

O procedimento consistiu em impor ao material diferentes velocidades de rotação (6,3 a 316,3 rpm) em patamares de $5 \mathrm{~s}$, primeiro acelerando e depois desacelerando, conforme a Figura 5. Foram utilizados os valores de torque representativos de cada patamar para a confecção das curvas de torque vs. rotação, consideradas na análise (CARDOSO, 2009).

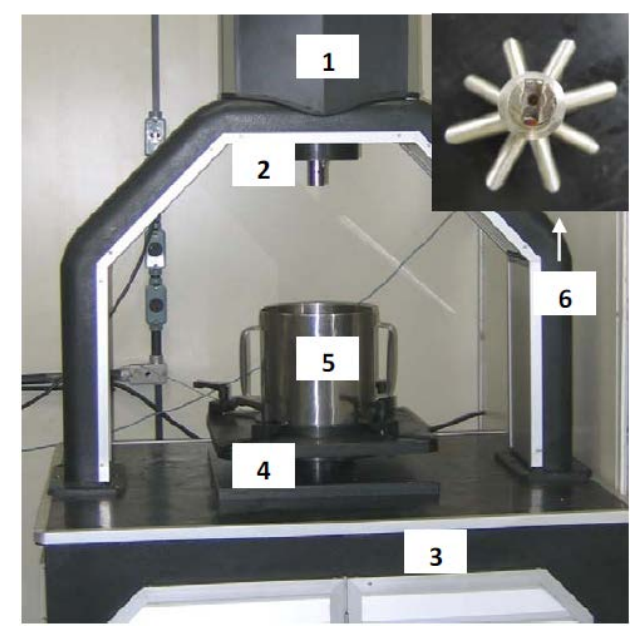

Figura 4 - Reômetro com destaque para seus componentes

Fonte: Cardoso (2009).

Nota: Legenda:

1) torre superior;

2) dispositivo rotacional;

3) base de reação e console;

4) elevador; 5) recipiente de ensaio;

6) geometria de mistura e ensaio composta por aletas radiais montadas em espiral.

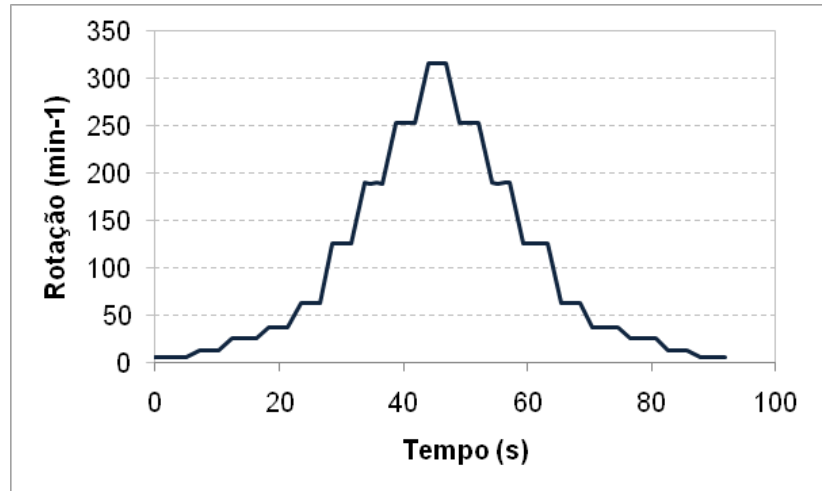

Figura 5 - Programa de rotações do teste de ciclo de cisalhamento

168 França, M. S. De; Cardoso, F. A.; Pileggi, R. G. 
E, por fim, o teor de ar incorporado foi avaliado segundo o método estabelecido pela ABNT NBR 13278 (ABNT, 2005). Os valores de teor de ar obtidos variaram entre $2 \%$ e $3 \%$ nas argamassas sem o aditivo - REF, e para as argamassas com o dispersante - DIS, o teor de ar foi em média $4 \%$.

\section{Resultados e discussão}

\section{Curvas de mistura e ciclos de cisalhamento}

Na Figura 6 estão representados os gráficos das misturas sem dispersante - REF e com dispersante - DIS, nos tempos analisados. O líquido é introduzido no sistema no instante inicial (tempo = $0 \mathrm{~s}$ ) e o término de adição ocorre em tempo = $5 \mathrm{~s}$.

Nas curvas de mistura os parâmetros importantes de ser avaliados são o torque máximo atingido, torque final, tempo para atingir torque constante e a área sob a curva. Esta última é um indicativo da energia envolvida no processo (OLIVEIRA et al., 2000; PILEGGI, 2001; PILEGGI; STUDART; PANDOLFELLI, 2001; CARDOSO, 2009).

Conforme pode ser visualizado nas curvas da Figura 6, no momento em que o líquido é introduzido no sistema ocorre uma elevação dos níveis de torque, atingindo rapidamente o nível de torque máximo.

O aumento desses níveis de torque ocorre em função do aumento das forças capilares, uma vez que toda a água é adicionada em 5 s, ou seja, numa taxa de adição elevada, levando a uma rápida
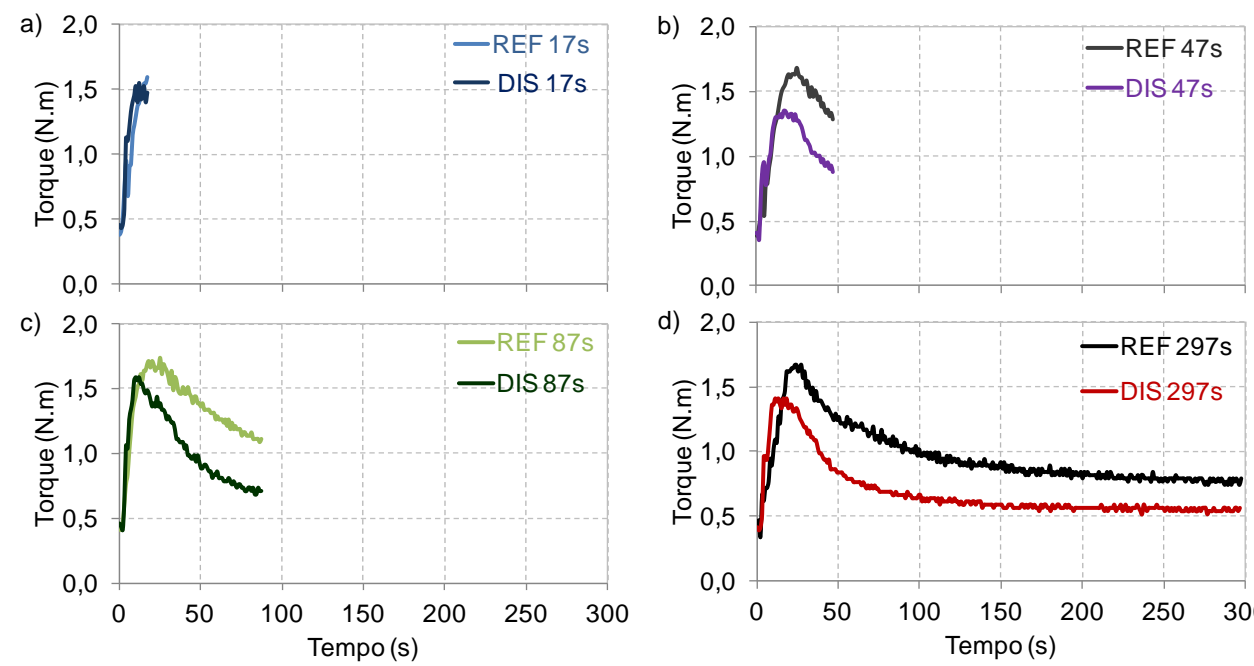

Figura 6 - Curvas de mistura torque vs. tempo para argamassas sem dispersante - REF e com dispersante - DIS

Nota: Legenda:
a) $17 \mathrm{~s}$;
b) $47 \mathrm{~s}$;
c) $87 \mathrm{~s}$; e
d) $297 \mathrm{~s}$.

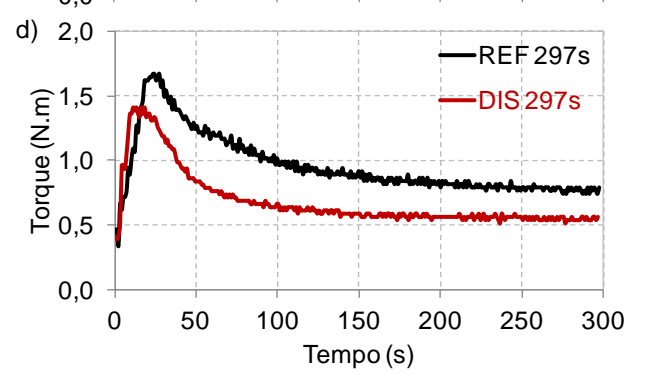

formação e crescimento dos aglomerados. O sistema alcança um estado de saturação máxima também nos primeiros instantes de mistura, diminuindo consequentemente as forças capilares, pelo afastamento das partículas, e a resistência dos aglomerados inicialmente formados, conduzindo, assim, a uma diminuição dos níveis de torque (KRISTENSEN; HOLM; SCHAEFER, 1985; KNIGHT et al., 1998; IVESON et al., 2001; PILEGGI, 2001; CAZACLIU; ROQUET, 2009).

Nas curvas apresentadas na Figura 6a, o material é misturado por $17 \mathrm{~s}$. Nota-se que a mistura foi interrompida no momento em que atingia o torque máximo ou até um pouco antes disso, como mostra a curva REF, um forte indicativo de que foram formados aglomerados; entretanto, o tempo de mistura não foi suficiente para destruí-los.

À medida que o tempo de mistura aumenta, observa-se uma diminuição dos níveis de torque após atingir seu máximo (Figuras 6b, c, d) indicando menor resistência ao fluxo, ou seja, os aglomerados formados inicialmente estão sendo destruídos pela ação cisalhante da mistura. A partir de 87 s (Figura 6c), observa-se que o sistema entra no que pode ser chamado de regime de fluidez, estabilizando o torque a níveis constantes.

Quando o material é submetido a um tempo de mistura razoavelmente longo (297 s), é possível observar a tendência à estabilização, uma vez que as curvas (Figura 6d) alcançam níveis de torque constantes, indicando que o sistema encontra-se estável e fluido, principalmente quando o dispersante está presente. 
A ação do aditivo dispersante é percebida nas curvas DIS (Figura 6), reduzindo os níveis de torque máximo e iniciando a estabilização do sistema em tempos mais curtos que o sistema REF.

Oliveira et al. (2003), investigando a influência de diferentes tipos de aditivos na reologia de concretos refratários, sugeriram que menores níveis de torque estão associados a uma melhor dispersão das partículas, uma vez que o sistema adequadamente disperso oferece menor resistência ao cisalhamento, reduzindo o torque necessário para misturá-lo em uma determinada rotação.

Após ser misturado, o material foi submetido a três ciclos de cisalhamento consecutivos, cujas curvas
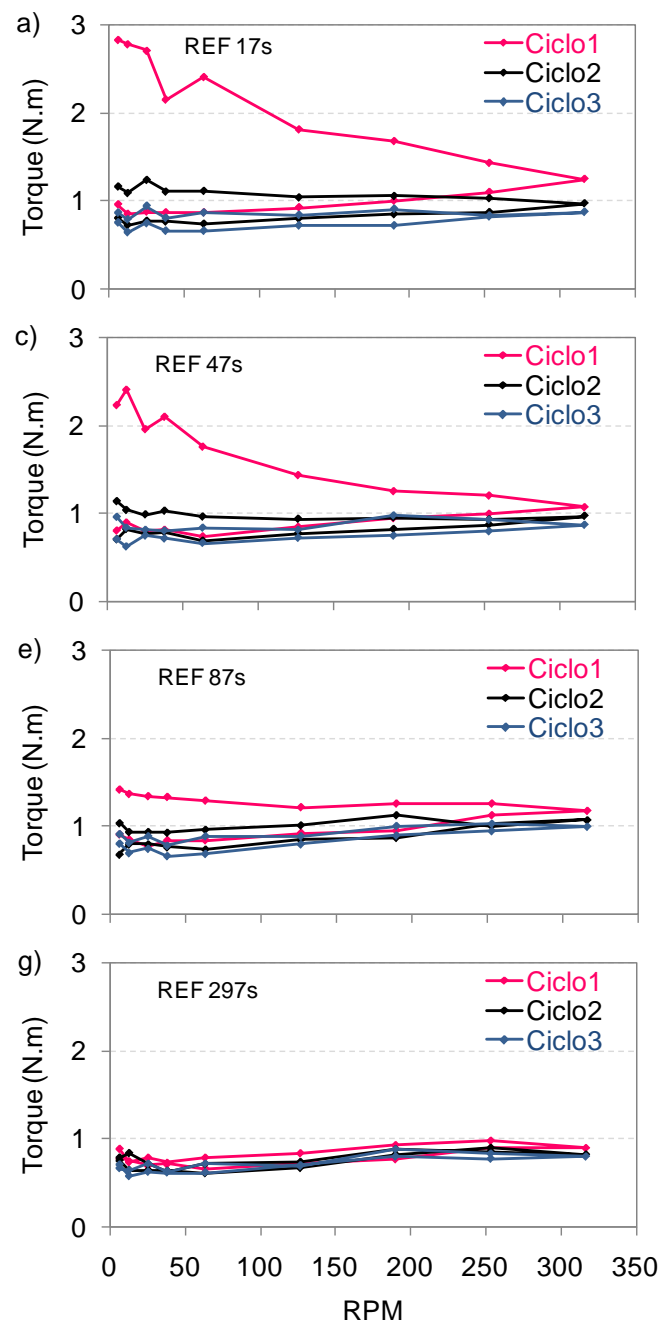

Figura 7 - Ciclos de cisalhamento

Nota: Legenda:
a) REF $17 \mathrm{~s}$;
b) DIS $17 \mathrm{~s}$;
c) REF $47 \mathrm{~s}$;
d) DIS $47 \mathrm{~s}$;
e) REF $87 \mathrm{~s}$;
f) DIS $87 \mathrm{~s}$;
g) REF $297 \mathrm{~s}$; e
h) DIS $297 \mathrm{~s}$

estão apresentadas na Figura 7. Essa metodologia é uma maneira de avaliar-se o quanto a mistura foi eficiente, além de inferir sobre seu comportamento reológico. Duas informações básicas são fornecidas pelos ciclos:

(a) a área de histerese (diferença de torque entre aceleração e desaceleração), que indica o estado de dispersão; e

(b) o nível e perfil da curva de torque em função da rotação, que representa o comportamento reológico do material (PILEGGI; STUDART; PANDOLFELLI, 2001).
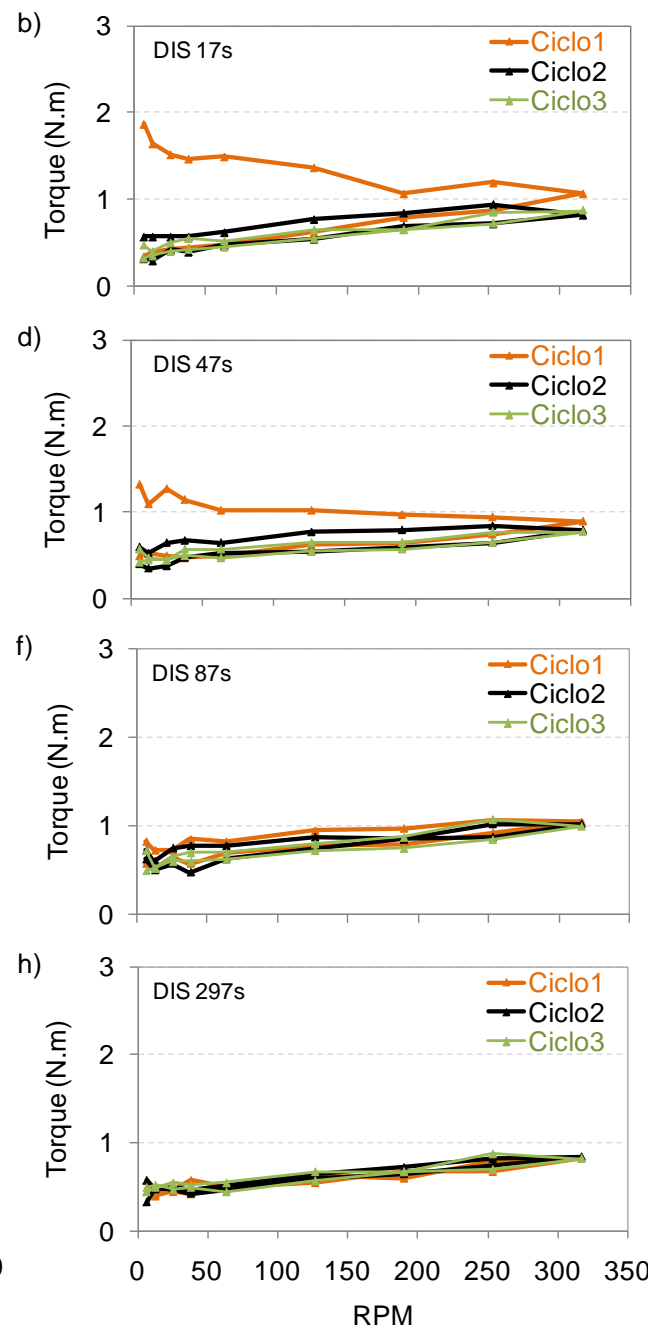
Eles fornecem energia adicional à fornecida durante a mistura para a quebra de eventuais aglomerados presentes (OLIVEIRA et al., 2003). $\mathrm{O}$ efeito do cisalhamento não só orienta as partículas na suspensão como também quebra as ligações fracas entre as partículas aglomeradas (FERNÀNDEZ-ALTABLE; CASANOVA, 2006).

Observando as curvas (Figura 7), é possível fazer as constatações a seguir. Primeiramente, percebese que o sistema DIS apresenta níveis de torque mais baixos que o sistema REF. Segundo, que o ciclo 1 é responsável pelas maiores variações entre aceleração e desaceleração (área de histerese). A histerese está relacionada com a estrutura interna do material. Áreas de histerese grande indicam que o processo de mistura não suprimiu a energia requerida para a quebra de todos os aglomerados, então a quebra destes deve acontecer nos ciclos de cisalhamento. Quando a área de histerese é pequena e os ciclos não se diferenciam entre si, isso sinaliza que a mistura foi eficiente e que os aglomerados foram destruídos nessa etapa (FERNÀNDEZ-ALTABLE; CASANOVA, 2006; PILEGGI; STUDART; PANDOLFELLI, 2001). E, por fim, à medida que se aumenta o tempo de mistura, mais estável reologicamente se comporta o sistema. Esse fato é verificado a partir de $87 \mathrm{~s}$ de mistura.

\section{Análise da energia envolvida}

A energia envolvida no processo de mistura é estimada por meio da área abaixo da curva torque vs. tempo (Figura 6). A quantificação obtida pode ser visualizada no gráfico da Figura 8.

Como pode ser visto na Figura 8a, a energia de mistura segue aumentando conforme o tempo de mistura aumenta. Com a introdução do aditivo dispersante, a energia de mistura é reduzida, exceto em 17 s de mistura, cujo valor foi um pouco maior, porém não muito expressivo comparando com a argamassa sem o dispersante - REF. Isso pode ser um indicativo de que em tempos estritamente curtos a presença do dispersante é pouco expressiva, ou que o tempo não foi suficiente para que o aditivo iniciasse sua atuação. Porém, quando o sistema é submetido aos ciclos de cisalhamento (Figura 8b), a energia adicional fornecida por esses conduz a níveis mais baixos de energia, até mesmo em $17 \mathrm{~s}$ de mistura.
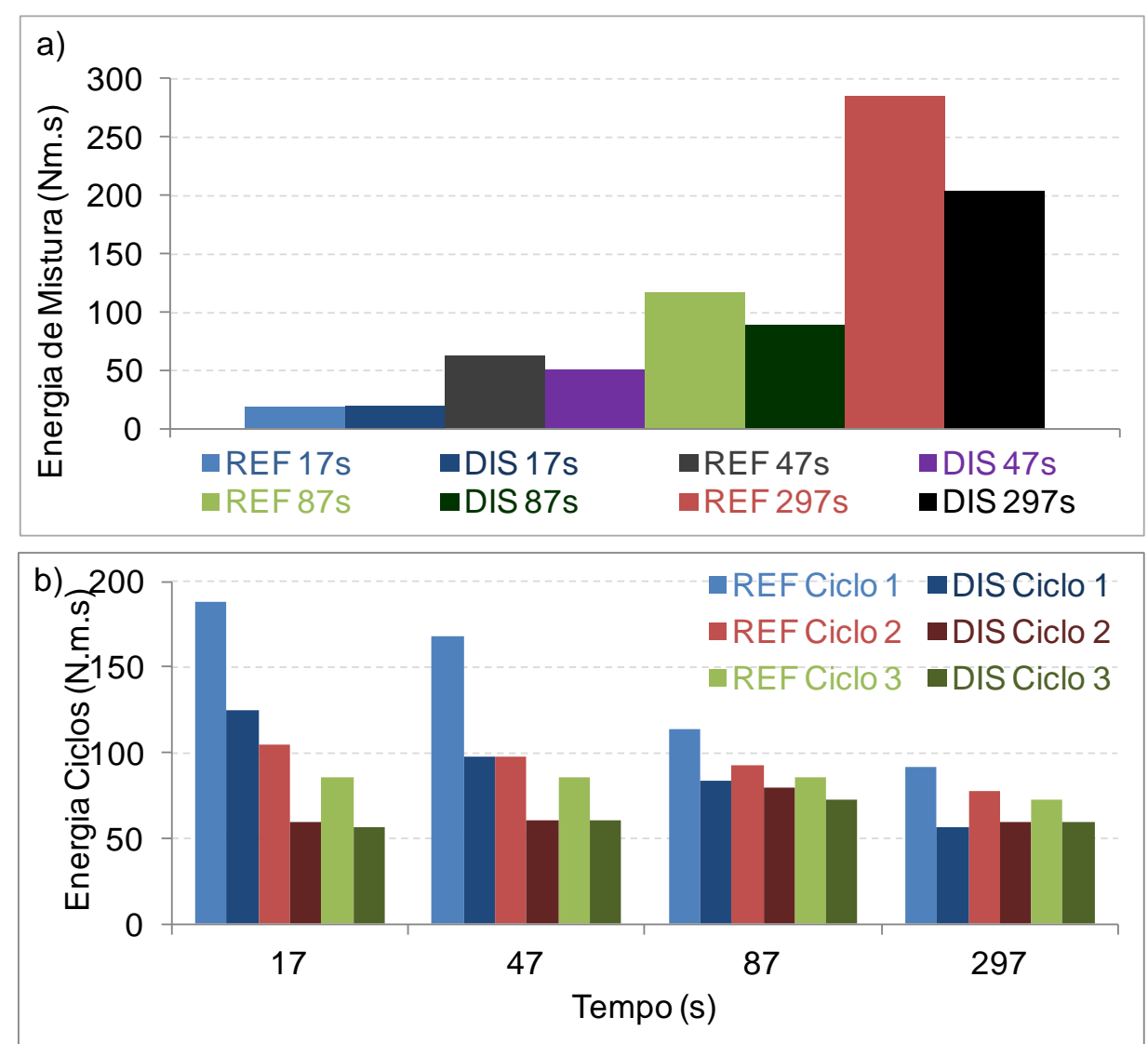

Figura 8 - (a) Energia envolvida em cada tempo de mistura - REF e DIS e (b) Energia envolvida nos ciclos 
Pela análise conjunta, primeiro da energia envolvida na mistura e, em seguida, da energia envolvida nos ciclos (Figura 8), observa-se que, quanto maior a energia de mistura, menor é a energia resultante nos ciclos, especialmente no primeiro. Quanto mais eficiente é o processo de mistura, maior a homogeneização e a dispersão (menor o tamanho das unidades móveis, partículas ou aglomerados) do sistema. Desse modo, durante os ciclos o material apresenta menor resistência ao cisalhamento imposto e um comportamento mais fluido.

Outro ponto relevante é que a energia envolvida no sistema DIS foi menor que a outra REF (Figura 8). Isso pode ser associado ao fato de o policarboxilato de sódio promover o molhamento das partículas e possibilitar a homogeneização da suspensão, e por conferir forças repulsivas entre as partículas, reduzindo ou eliminando a adesão entre elas, o que provoca níveis de torque mais baixos como resposta (OLIVEIRA et al., 2003; FLATT; MARTYS; BERGSTRÖM, 2004).

Uma consideração ainda a ser feita nesse aspecto de quantificação de energia envolvida no processo de mistura é correlacionar a área de histerese com a energia acumulada na mistura e nos ciclos de cisalhamento. Na Figura 9 estão ilustrados os gráficos que relacionam essas duas grandezas.

No gráfico da Figura 9a, a área de histerese das composições segue diminuindo com a sequência dos ciclos. No primeiro ciclo de cisalhamento a diferença é bem acentuada; quanto menor o tempo de mistura, maior esta área. Ênfase é dada à mistura de 297 s, cujas áreas de histerese dos ciclos quase não variam, principalmente nos dois últimos, ou seja, os ciclos mostraram que um tempo de mistura maior contribui para a homogeneidade do sistema.
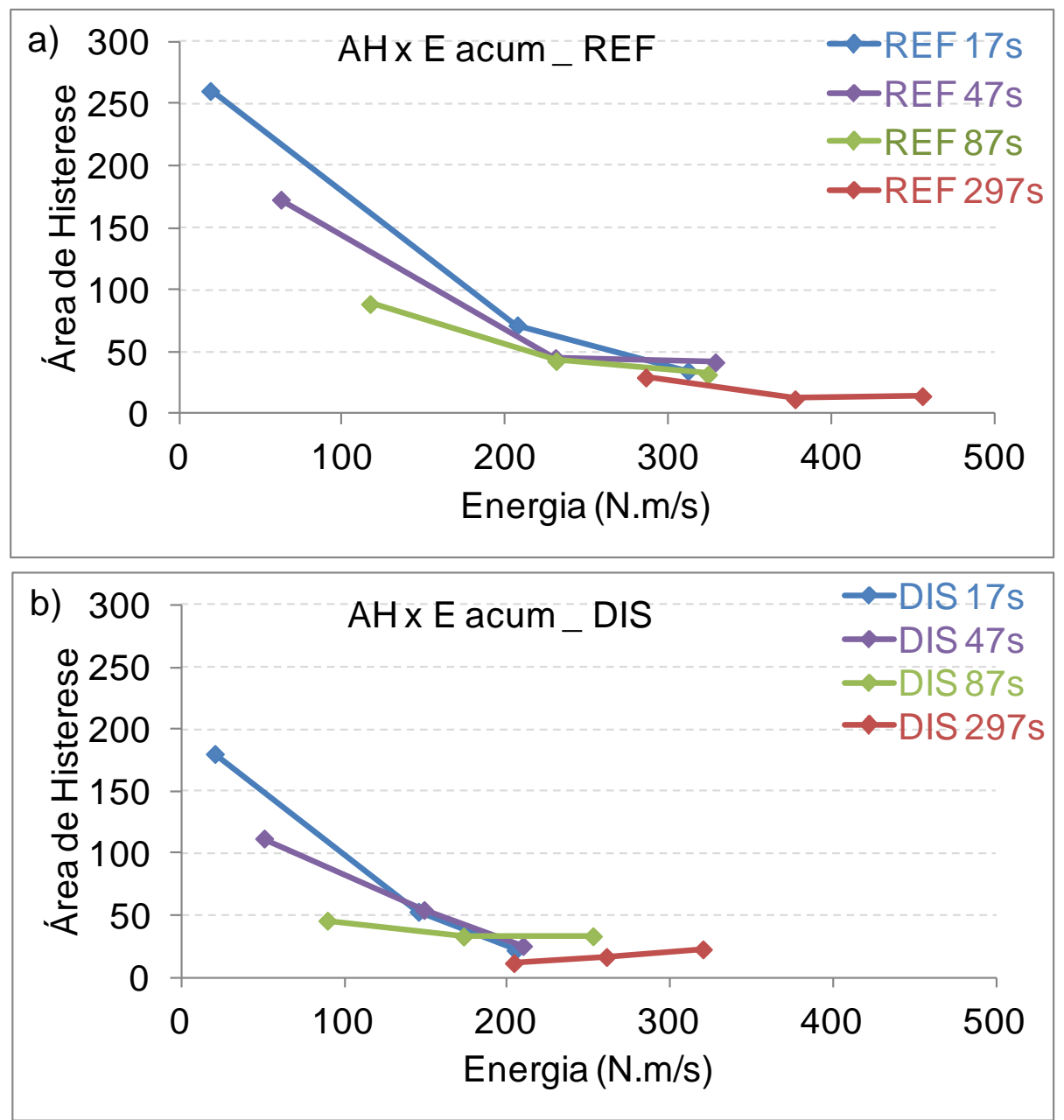

Figura 9 - Curvas que relacionam a área de histerese com a energia acumulada no início do ciclo de cisalhamento 
Na Figura 9b, por sua vez, essa tendência é perceptível nos dois primeiros tempos (17 s e 47 s) de mistura avaliados. Em 87 s de mistura observase maior linearidade entre os ciclos de cisalhamento que as observadas em todas as outras. E para 297 s de mistura a área de histerese dos ciclos de cisalhamento teve um leve crescimento do primeiro até o último (Figura 9b). Essa diferença é tão sutil que quase passa despercebida na Figura 7h, sugerindo que, após o processo de mistura, os ciclos de cisalhamento praticamente não tenham sofrido mudanças, indicando que o sistema já se encontra estável.

Por fim, pela análise da Figura 9, pode-se dizer que os sistemas tendem a estabilizar-se com o aumento do tempo de mistura, atingindo áreas de histerese cada vez mais baixas, e que o sistema com dispersante tende a estabilizar-se com um nível de energia bem mais baixo que o outro sistema sem dispersante.

\section{Conclusões}

A metodologia utilizada - reometria de mistura seguida de ciclos de cisalhamento consecutivos demonstrou ser uma valiosa ferramenta para o estudo do comportamento de mistura de argamassas, sendo capaz de avaliar a eficiência do processo de mistura e sua associação com os comportamentos reológicos resultantes.

O comportamento reológico de argamassa é significativamente influenciado pelo tempo de mistura e pela presença do dispersante. Em tempos curtos verificou-se que a mistura não conseguiu romper totalmente os aglomerados formados imediatamente após a adição de água, resultando em materiais reologicamente instáveis e menos fluidos, principalmente durante a aplicação do primeiro ciclo. Nesses casos, os sistemas necessitaram da energia extra fornecida pelos ciclos de cisalhamento para homogeneização e quebra dos aglomerados ainda existentes após a etapa de mistura.

Por sua vez, um tempo de mistura maior demonstrou ser mais eficiente devido à maior energia envolvida no processo, produzindo uma argamassa dispersa, homogênea, estável e fluida. As curvas reológicas (ciclos) apresentam os menores torques iniciais (parâmetro relacionado à tensão de escoamento) e as menores inclinações (parâmetro relacionado à viscosidade), e praticamente não há variação entre os trechos de aceleração e desaceleração (baixa área de histerese) e nem entre os ciclos.

\section{Referências}

ASSOCIAÇÃO BRASILEIRA DE NORMAS
TÉCNICAS. NBR 13278: argamassa para

assentamento e revestimento de paredes e tetos: determinação da densidade de massa e do teor de ar incorporado. Rio de Janeiro, 2005.

CARDOSO, F. A. Método de Formulação de Argamassas de Revestimento Baseado em Distribuição Granulométrica e Comportamento Reológico. São Paulo, 2009. Tese (Doutorado) Departamento de Engenharia Civil, Escola Politécnica, Universidade de São Paulo, São Paulo, 2009.

CAZACLIU, B.; LEGRAND, J. Characterization of the Granular-to-Fluid State Process During Mixing by Power Evolution in a Planetary Concrete Mixer. Chemical Engineering Science, v. 63, n. 18, p. 4617-4630, 2008.

CAZACLIU, B.; ROQUET, N. Concrete Mixing Kinetics by Means of Power Measurement.

Cement and Concrete Research, v. 39, n. 8, p. 182-194, 2009.

FERNÀNDEZ-ALTABLE, V.; CASANOVA, I. Influence of Mixing Sequence and Superplasticiser Dosage on the Rheological Response of Cement Pastes at Different Temperatures. Cement and Concrete Research, v. 36, p. 1222-1230, 2006.

FLATT, R. J.; MARTYS, N. S.; BERGSTRÖM, L. The Rheology of Cementitious Materials.

Materials Research Society Bulletin, v. 29, n. 5, p. 314-318, 2004.

IVESON, S. M. et al. Nucleation, Growth and Breakage Phenomena in Agited Wet Granulation Processes: a review. Powder Technology, v. 117, n. 1/2, p. 3-39, 2001.

KNIGHT, P. C. et al. An Investigation Into the Kinetics of Liquid Distribution and Growth in High Shear Mixer Agglomeration. Powder Technology, v. 97, p. 246-257, 1998.

KRISTENSEN, H. G.; HOLM, P.; SCHAEFER, T. Mechanical Properties of Moist Agglomerates in Relation to Granulation Mechanisms: part I: deformability of moist, densified agglomerates.

Powder Technology, v. 44, p. 227-237, 1985.

OLIVEIRA, I. R. et al. Dispersão e Comportamento Reológico de Concretos Refratários Ultra-Baixo Teor de Cimento no Sistema Al2O3-SiC-SiO2-C. Cerâmica, v. 49, p. 17-22, 2003.

OLIVEIRA, I. R. et al. Dispersão e

Empacotamento de Partículas: princípios e aplicações em processamento cerâmico. São Paulo: Fazendo Arte, 2000. 195 p. 
PILEGGI, R. G. Ferramentas Para o Estudo e Desenvolvimento de Concretos Refratários. 187 f. São Carlos, 2001. Tese (Doutorado em Ciência e Engenharia de Materiais) - Programa de PósGraduação em Ciência e Engenharia de Materiais, Universidade Federal de São Carlos, São Carlos, 2001.

PILEGGI, R. G.; STUDART, A. R.;

PANDOLFELLI, V. C. How Mixing Affects the Rheology of Refractory Castables, PART 1, PART 2. American Ceramic Society Bulletin, v. 80, n. 6, p. 27-42, 2001.

VAN DEN DRIES, K. The Paradox of High

Shear Granulation: the formation of nonhomogeneous granules. Netherlands, 2004. PhD Thesis - Utrecht University, Utrecht, 2004.
WILLIAMS, D. A.; SAAK, A.; JENNINGS, H. $\mathrm{M}$. The Influence of Mixing on the Rheology of Fresh Cement Paste. Cement and Concrete Research, v. 29, n. 9, p. 1491-1496, 1999.

YAMMINE, J. et al. From Ordinary Concrete to Self Compacting Concrete: a transition between frictional and hydrodynamic interactions. Cement and Concrete Research, v. 38, n. 7, p. 890-896, 2008.

YANG, M.; JENNINGS, H. M. Influences of Mixing Methods on the Microstructure and Rheological Behavior of Cement Paste. Advanced Cement Based Materials, v. 2, p. 70-78, 1995.

Revista Ambiente Construído

Associação Nacional de Tecnologia do Ambiente Construído

Av. Osvaldo Aranha, 99 - 3o andar, Centro

Porto Alegre - RS - Brasil

CEP $90035-190$

Telefone: +55 (51) 3308-4084

Fax: +55 (51) 3308-4054

www. seer. ufrgs. br/ ambienteconstruido

E-mail: ambienteconstruido@ufrgs.br

174 França, M. S. De; Cardoso, F. A.; Pileggi, R. G. 